Trajes do clero: diálogos sobre patrimônio, poder e comunicação

\title{
Trajes do clero: diálogos sobre patrimônio, poder e comunicação
}

Renilda Santos do Vale ${ }^{1}$

\section{Resumo:}

O presente artigo tem por finalidade analisar o vestuário como patrimônio importante no estudo das relações do homem com a sociedade, o poder hierárquico e simbólico exercido através dos trajes utilizados pelos sacerdotes durante as celebrações litúrgicas e a importância do valor intrínseco e atribuído desse objeto da cultura material. Utilizando como objeto de pesquisa peças da coleção de trajes eclesiásticos do Museu do Traje do Têxtil da Fundação Instituto Feminino da Bahia (FIFB).

Palavras Chaves: indumentária litúrgica, Instituto Feminino, hierarquia, comunicação e poder.

\begin{abstract}
:
The present article has purpose to analyse clothes as important patrimony in the study of the relations of the man with society, the hierarchic and symbolic power exerted through the suits used for the priests during the liturgical celebrations and the importance of the intrinsic and attributed value of this object on the material culture. Using as research object parts of the collection ecclesiastical Suits of the Museum of the Suit of the Textile of the Foundation Feminine Institute of the Bahia.

Keywords: liturgical cloth, Feminine Institute, hierarchy, communication and power.

\footnotetext{
${ }^{1}$ Museóloga, mestra pelo Programa de Pós Graduação de Museologia (PPGMUSEU) da Faculdade de Filosofia e Ciências Humanas (FFCH) da Universidade Federal da Bahia (UFBA).Contato: renildadovale@yahoo.com.br
} 
Renilda Santos do Vale

\section{0 vestuário, o homem e as relações de poder}

Muitos e variados são os objetos que fazem parte do dia a dia do ser humano. Esta relação do homem e da mulher com os objetos parece ser tão simples, tão normal com alguns deles que se tem a impressão de que é quase impossível não tê-los no cotidiano da vida, como por exemplo, o copo de vidro, a toalha de banho ou os sapatos. Às vezes temos alguns por grande necessidade, como foram vistos no exemplo, e outras vezes por puro prazer e outras ainda por não sabermos mais como viver sem eles, mesmo quando estes podem ser substituídos.

Confeccionados com materiais diversos - plásticos, metais, madeiras, tecidos, cerâmica, vidro etc., os objetos estão presentes na história da humanidade desde a antiguidade e são os grandes colaboradores para representar cada período da história, de modo que, por meio deles, identifica-se o tempo, os povos e suas culturas, analisam-se os fatos. Desse modo, pode-se então afirmar que é "O objeto, síntese dessas representações de mundo, documento material das articulações entre o homem e seus universos perceptivos". (Sheiner, 2009, p. 91). Como esclarece Sheiner o objeto é uma síntese das representações de mundo, ou seja resume em si as relações entre os homens com o que está em sua volta. O comportamento, usos e costumes de cada tempo podem ser analisados através deles. A leitura dos objetos podem revelar muito mais do que se imagina, mas é necessário aprender a lê-los. "Se aprendemos a ler palavras, é preciso exercitar o ato de ler objetos, de observar a história que há na materialidade das coisas. Além de interpretar a história através dos livros, é plausível estuda-la por meio de objetos". (Ramos, 2014, p. 21-22).

São diversos, os tipos de "coisas" de uso pessoal ou coletivo, utilizados no dia a dia, esses objetos são usados pelas pessoas na maioria das vezes sem que elas nunca tenham feito uma 
Trajes do clero: diálogos sobre patrimônio, poder e comunicação

reflexão sobre eles, sem pensar. E é muitas vezes dessa mesma forma que esses artefatos chegam aos museus e por eles recebem uma nova utilização e uma nova leitura. Chegam e se tornam objetos musealizados ${ }^{2}$ com a mesma deficiência de quando ainda estavam em circulação, porque pouco se pensa, reflete ou analisase sobre eles. Essa falta de reflexão do objeto traz por consequência a carência de conteúdo teórico sobre o mesmo, o que se torna um problema, principalmente quando estes passam a fazer parte dos acervos dos museus, pois se pequena é a percepção que se tem dos objetos em uso, pequena também será a percepção do público quando os encontram nos museus. Sobre isso esclarece Ramos (2004)

No cotidiano, usamos uma infinidade de objetos: desde a televisão até uma roupa. Por outro lado, pouco pensamos sobre os objetos que nos cercam. Se pouco refletimos sobre nossos próprios objetos, a nossa percepção de objetos no museu será também de reduzida abrangência. Sem o ato de pensar sobre o presente vivido, não há meios de construir conhecimento sobre o passado. E o próprio conhecimento do presente já pressupõe referências ao pretérito. (p. 21).

Entretanto, como afirma o mesmo autor na citação anterior "Se aprendemos a ler palavras, é preciso exercitar o ato de ler objetos" (Ramos, 2004, p. 21), ou seja, assim como se aprende a ler palavras é necessário ensinar a ler objetos, mas isso deve começar a acontecer quando estes ainda estão com sua função original,

2 A musealização é o "processo pelo qual um objeto ao ser retirado do fluxo cotidiano integra uma coleção museológica e passa a ter um valor de representação. O processo de musealização implica todas as etapas do sistema de ações museológicas. ((Texto extraído do Glossário do Caderno de Diretrizes "Documentação e Conservação de Acervos". (Associação Cultural de Amigos do Museu Casa de Portinari [ACAM Portinari], 2010, p. 103). 
assim se entenderá com mais clareza sua nova funcionalidade quando estiverem expostos nos museus.

Alguns objetos estão há tanto tempo nas sociedades que se tem a impressão de que sempre existiram. São móveis, vestuários, eletrodomésticos, acessórios... objetos, de todo tipo e valor. Através deles a história pode ser contada, eles têm o poder de ilustrarem a história. Nos museus, entre outras coisas se torna necessário saber como eram utilizados, por quem, em que contexto surgiram, se tornaram valorizados, desvalorizados, esquecidos ou lembrados.

Entre essa infinidade de objetos está o tecido, intrigante objeto que parece exercer com a mesma força tanto as funções concretas quanto as simbólicas. Protege e ao mesmo tempo exibe o corpo. Os tecidos fazem parte do grupo de coisas com que o ser humano é sempre visto. Para Peter Burke ), "A maioria dos estudos sobre cultura material enfatiza o clássico trio de temas - alimentos, vestuário e habitação" (como citado em Vale, 2005, p. 13), provavelmente por serem estes os que nos acompanham durante toda a nossa vida. Porém, talvez nenhum deles seja tão significativo, quanto os tecidos, mas, apesar disso, como se pode notar:

Poucas vezes nos detivemos a pensar nos tecidos como objetos mais importantes para o homem; o acompanha desde que nasce até a morte. Desde o ser mais humilde até o mais rico está rodeado de tecidos. É possível que em nossas casas não tenhamos uma pintura, uma escultura, mas sempre haverá tecidos. (Carvajal, 2000, p. 11).

Se no início o principal objetivo do traje era proteger o corpo, hoje são inúmeros os motivos que movem o homem a vestirse. Os valores simbólicos logo apareceram e foram agregados ao ato de cobrir o corpo. Para alguns autores isso não demorou muito para acontecer, ou melhor dizendo, veio logo em seguida, ainda 
Trajes do clero: diálogos sobre patrimônio, poder e comunicação

com o homem primitivo e seus trajes de pele, que além de proteger, comunicavam aos outros (os que não possuíam peles) a força e o poder de quem os tinham (Vale, 2015). Em certo momento, esses primeiros trajes passaram a ser muito mais desejados por aquilo que representavam do que pela sua própria funcionalidade, como reflete Humberto Eco (1989).

E há casos em que o objeto perde a tal ponto a sua funcionalidade física e adquire um valor comunicativo a tal ponto que se torna acima de tudo um sinal, e permanece objeto apenas em segunda instância. A moda é um destes casos. Basta o exemplo da pele envergada pelo nosso homem primitivo por razões essencialmente funcionais. Tinha frio e cobria-se, não há dúvida. Mas também não há dúvida que no espaço de poucos dias depois da invenção do primeiro traje de peles, se terá criado a distinção entre os bons caçadores munidos das suas peles, conquistadas pelo preço de uma dura luta, e os outros, os inaptos, os sem-peles. E não é precisa muita imaginação para imaginar a circunstância social em que os caçadores terão envergado as peles, já não para proteger-se do frio, mas para afirmar que pertenciam à classe dominante. (p. 15).

Pensando assim, Eco leva o leitor a uma reflexão profunda sobre o ato de vestir-se, pois segundo ele, tal ato desde os primórdios não estava associado apenas a vontade do homem e da mulher de cobrir ou proteger o corpo, mas, mais do que isso, o homem primitivo pode ter descoberto que o uso das peles dos animais , "conquistadas pelo preço de uma dura luta", trazia a ele, o respeito e a admiração dos outros, os distinguiam, pois o seu uso poderia ser associado ao poder, como afirma Eco, dessa forma estes passavam a fazer parte da classe dominante.

Nos dias de hoje, os tecidos, de modo especial os trajes, estão associados a variados fatores, classes e designações. Por eles se faz distinções e se julga o status do indivíduo. Por eles se pode 
chegar a uma constatação, mesmo que esta não seja verdadeira. Um exemplo disso são as marcas famosas de roupas, que podem revelar o poder aquisitivo daqueles que as usam, ou apenas serem usadas por alguém que deseja ser visto dessa forma.

Há casos em que o poder hierárquico pode ser definido por meio deles, são então usados como sinais, comunicam de forma silenciosa, quem é o indivíduo que o está vestindo, ou melhor dizendo, o que ele representa, um exemplo disso é a toga ${ }^{3}$ usada pelos juízes, estes são reconhecidos por aquilo que vestem. Segundo Cambell "Quando um juiz adentra o recinto de um tribunal e todos se levantam, não estão se levantando para o indivíduo, mas para a toga que ele veste e para o papel que ele vai desempenhar", (como citado por Hostalácio, 2015, p. 4).

Do mesmo modo, muitas religiões utilizam o vestuário para identificarem a fé que professam e o grau hierárquico de seus representantes. Quando se trata de indumentária católica, pode-se identificar no uso dos trajes litúrgicos a hierarquia eclesiástica, identificada pela utilização destes destinados aos ministros ordenados (diáconos, presbíteros, bispos, cardeais e papas). No caso de algumas peças que são de uso comum, estes são diferenciados muitas vezes por detalhes nas tonalidades e pelas insígnias pontificais ${ }^{4}$ ou mesmo pela forma de uso.

3 Segundo Hostalácio (2015) “Togas são vestes talares - o vocábulo "talar" vem do latim talus, que significa calcanhar -, vestimentas cujo comprimento vai até os calcanhares. É um traje, assim como as becas e as batinas, que simboliza poder, dando especial representatividade a quem os usa. No caso da vestimenta usada pelo Judiciário, a cor preta enfatiza essas características, e há quem afirme que apenas magistrados podem usar toga - as becas se destinariam a membros do Ministério Público e operadores do direito, entre outros".(p. 4).

4 "Do latim insígnia [insígnias], distintivos. São usadas por pessoas ou autorizadas ou conforme sua posição no ministério eclesiástico. São conhecidas de modo especial as insígnias pontificais do bispo: Cátedra, báculo (episcopal), anel, mitra, cruz peitoral e palio; e para os sacerdotes e diáconos, a estola". (Bexten \&Urban, 2013, p.134). 
Trajes do clero: diálogos sobre patrimônio, poder e comunicação

\section{Os objetos e os valores atribuídos a eles}

Parte das principais peças que compõe a Coleção Eclesiástica do Museu do Traje e do Têxtil da Fundação Instituto Feminino da Bahia, ${ }^{5}$ pertence a Catedral Basílica de Salvador. Portanto, essa coleção traz em si parte da história da sociedade baiana. Vale lembrar que "A Diocese de São Salvador da Bahia foi criada a 25 de fevereiro de 1551 pela Bula Super specula militantis ecclesiae do Papa Júlio III. A 16 de novembro de 1676, pela Bula Inter Pastoralis Offi cii Curas do Papa Inocêncio XI, foi elevada a Arquidiocese e Sede Metropolitana". ${ }^{6}$ Nesse sentido, o estudo dessa coleção (patrimônio da cidade de Salvador) se torna tão necessário, pois cada objeto guarda um pouco da história de quem fez parte dela, dentro de um contexto muito maior.

Além disso, algumas peças foram confeccionadas dentro do próprio Instituto Feminino, instituição que sempre esteve ligada a Igreja Católica, desde a sua fundação em 1923. O próprio Instituto possuía um atelier de costura, onde eram confeccionados muitos paramentos litúrgicos ${ }^{7}$ (algo ainda a ser pesquisado). Todas as

${ }^{5}$ A Fundação Instituto Feminino da Bahia (FIFB) é uma instituição privada, católica, sem fins lucrativos, com sede no bairro do Politeama na cidade de Salvador. Para mais informações visite o site: <http://www. institutofeminino.org.br /fundação

${ }^{6}$ Informações extraídas do site: http:// arquidiocesesalvador.org.br/ 2014/?page_ id $=257>$.

7 "Paramento é a designação comum para o conjunto de peças diretamente utilizadas na liturgia - casula, dalmática e tunicela, estola e manípulo distinguindo-se por uniformidade técnica e formal dos elementos constitutivos e representando as cores próprias dos tempos litúrgicos. Outras peças como o pluvial, bolsas, véus e frontal estão-lhe associadas, apresentando as mesmas características. Por vezes, peças apenas idênticas na corsão utilizadas como parte de um mesmo paramento, por já não existir as originais". (Alarcão \& Pereira, 2000, p. 59-60) 
informações nas peças e das peças estão também inseridas na história da Igreja Católica, pois a partir delas se pode desenhar um quadro traçado pela Arquidiocese da Bahia, principalmente entre os séculos XIX e XX, período em que o clero atravessou grandes mudanças no contexto social, político e econômico em que sempre esteve inserida. Sobre essa função do objeto, Pearce (2005) afirma:

Os objetos incorporam informações únicas sobre a natureza do homem na sociedade: nossa tarefa é a elucidação de abordagens através das quais isso possa ser recuperado, uma contribuição única que as coleções museológicas podem dar para a compreensão de nós mesmos. Os possíveis produtos dessa reflexão são bastante fascinantes por si sós, mas muitos subprodutos podem surgir nos caminhos pelos quais abordamos as exposições e o ensino (p. 13).

É justamente essa tarefa refletida por Pearce na citação acima que esse estudo pretende dar início, a partir da coleção de trajes eclesiásticos do Instituto Feminino da Bahia. As peças que a formam incorporam informações dessa instituição dentro do cenário da Bahia durante quase todo século $X X$, podem contribuir de modo significativo para compreensão desse período da história.

Segundo Ana Karina Oliveira (2009, p. 18) “O acervo de indumentária do Museu do Traje e do Têxtil do Instituto Feminino da Bahia-Salvador conta com mais de oito mil (8.000) peças", sendo que uma pequena parte dela é de trajes eclesiásticos, na qual se encontra peças do século XVIII ao século XX, um importante recorte histórico através desses objetos de cunho religioso que faziam parte da sociedade baiana católica desse período e que por causa do valor que lhes eram atribuídos sobreviveram e hoje podem ser explorados por profissionais pesquisadores de diversas áreas do conhecimento como a história, museologia, antropologia, teologia, moda ou qualquer outra área onde se estuda as relações sociais entre os homens. Nesse sentido reconhece-se que: 
Trajes do clero: diálogos sobre patrimônio, poder e comunicação

Os objetos são importantes para as pessoas porque atribuem prestígio e posição social; em termos sociais, a maioria das peças pertencentes às nossas coleções de vestuário, belas artes e artes aplicadas sobreviveu por essa razão. Os objetos - especialmente aqueles pertencentes às esferas religiosa e cerimonial ou aqueles constituídos de materiais de alto valor, como metais preciosos, marfim e âmbar - simbolizam, de modo único, estados mentais e relações sociais entre os homens e entre os homens e seus deuses. Objetos cerimoniais adquirem sua forma a partir da combinação de um ofício socialmente apropriado e dos impulsos provenientes de níveis profundos da psique humana. (Pearce, 2005, p. 19)

São atribuídos prestígio e posição social aos objetos pertencentes às esferas religiosa e cerimonial, como nos lembra Susan Pearce na citação acima. No caso da indumentária religiosa isso está estritamente ligado a cada peça. Além disso, o valor simbólico atribuído a estes, os torna objetos sacros o que já eleva e o distingue entre outras coisas, e dessa forma ele cumpre o papel para o qual foi criado, nesse sentido, muito bem colocado por Pearce "simbolizam de modo único, estados mentais e relações sociais entre os homens e entre os homens e seus deuses". (2005, p.19)

Para melhor elucidar essa relação simbólica na qual a indumentária possui muito mais que a simples função de proteger, cobrir, ou enfeitar o corpo e na qual há o que denomina-se de comunicação não verbal. São apresentadas a seguir duas peças da Coleção Eclesiástica do Museu do Traje e do Têxtil que se encontram na exposição de Longa duração "Relíquias da Fé". 


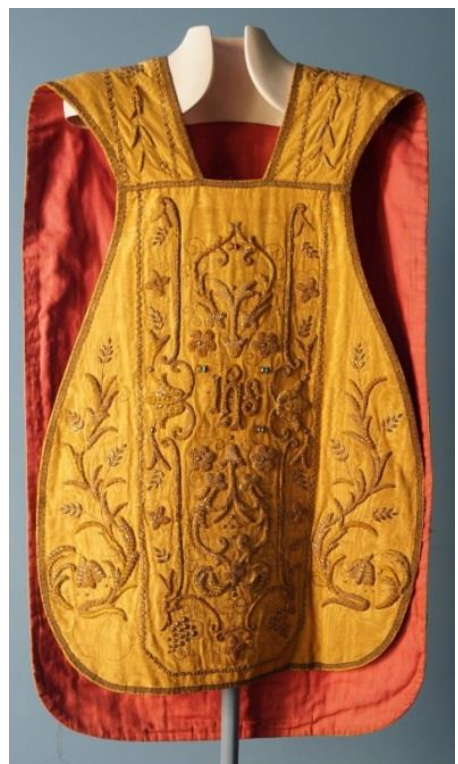

Imagem 1. Casula - acervo FIFB Fotografia: Renilda do Vale.

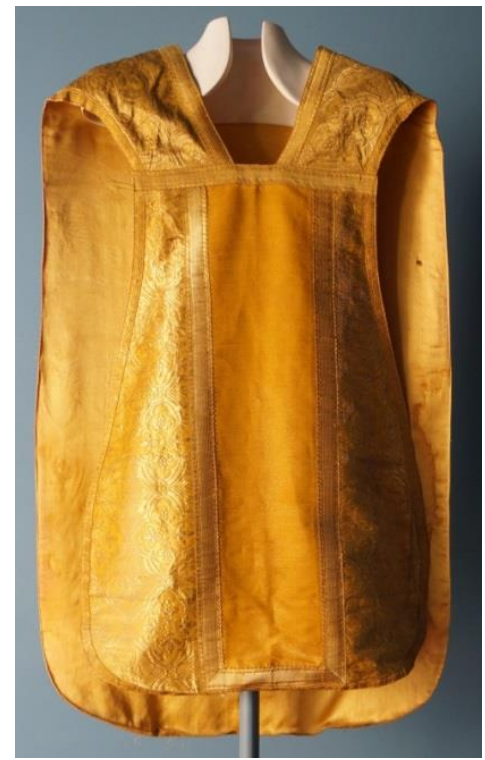

Imagem 2. Casula - acervo FIFB Fotografia: Renilda do Vale.

A primeira imagem (1) exibe uma casula, ${ }^{8}$ pertencente ao acervo da Catedral Basílica de São Salvador, sob a guarda do Museu do Traje e do Têxtil do Instituto Feminino da Bahia (FIFB)

8 Segundo Soraya Coppola (2006, p. 180) "Casula é a última peça sacerdotal a ser vestida. Fica sobre a túnica, estola, cíngulo e amito. Tem a mesma cor da estola e significa o poder do rei que Cristo tem. É uma peça que tem quase o tamanho da alva. Jesus é O Bom Pastor e o Rei do Mundo. Quando o padre não está usando a casula numa celebração da missa, ele é apenas o Cristo Bom Pastor, mas quando está usando a casula ele é o Cristo Rei do Universo, Cristo com toda a sua glória todo o seu poder. A Casula é usada em missas muito especiais, para mostrar a nobreza e a superioridade de Cristo o Rei do Universo, além de ser usada nas missas dominicais da igreja matriz da paróquia. O sacerdote ao vestir a Casula proclama: 'Serei sacerdote segundo a ordem de Melquisedec para a toda a eternidade'" 
Trajes do clero: diálogos sobre patrimônio, poder e comunicação

Casula confeccionada em tafetá de seda chamalotado amarelo, com motivos decorativos fitomorfos de folhas, flores e trigos em bordado cheio e fios dourados; pedras nas cores, vermelha, verde, azul e lilás. Datada do início do século XIX. Confeccionada em modelo romano com gola em ' $V$ ' e guarnição de galões formando colunas na frente e nas costas. Na frente ao centro também em bordado o trigrama IHS e nas costas ao centro também em bordado uma flor-de-lis. (Vale, 2016, p. 97)

Os detalhes com que foi confeccionada levam a crer que pertenceu a algum bispo. Algo também importante é a tonalidade da peça, aproximado ao dourado ou amarelo ouro, o que revela que era utilizada em missas solenes. Nos bordados encontram-se antigos e importantes símbolos do cristianismo como o trigo e a flor de lis em quase toda a extensão da casula. A flor de Lis é um símbolo que representa a presença da Virgem Maria. Talvez tal peça fosse usada apenas em missas solenes dedicadas a mãe de Jesus, como a festa da Assunção, a festa da Imaculada Conceição, a festa de Nossa Senhora Aparecida etc.

A segunda imagem (2) exibe umacasula do século $X X$, mais precisamente do ano de 1925, confeccionada em tela de ouro e brocado com bordado em matiz, com medalhão de São Vicente de Paulo (nas costas). Pertenceu a Monsenhor Flaviano Osório Pimentel, na tonalidade aproximado ao amarelo com detalhes em dourado. Porém, o que torna essa peça tão especial é o fato de ter pertencido a Monsenhor Flaviano, sacerdote, que em 1923 juntamente com D. Henriqueta Martins Catharino ajudou a criar a Fundação Instituto Feminino da Bahia, na época denominada Casa São Vicente. Funcionava em um casarão no Terreiro de Jesus e em 1929 passou a ser chamado de Instituto Feminino da Bahia. Monsenhor Flaviano faleceu em 1933. No seu 250 aniversário de morte, - dia 17 de julho de 1958 - , o Instituto Feminino da Bahia resolveu prestar grande homenagem ao seu fundador, que veio a ser realizada em 05 de Outubro, data em que o Instituto completou 
35 anos e coincidentemente data de aniversário de nascimento de Monsenhor Flaviano. Sobre ele Marieta Alves (2003) escreveu:

Outros 25 anos virão mais tarde. Incumbe aos que nos sucederem o dever de apontar a gratidão da juventude e da sociedade o nome de Mons. Flaviano Osório Pimentel, pioneiro da Obra de Proteção à mulher, na Bahia, fundador desse Instituto onde há 35 anos sob sua inspiração e exemplo, se procura fazer o bem, difundir a sã cultura e trabalhar para a maior glória de Deus. ( $p$. 27).

O valor atribuído a peça que pertenceu a Monsenhor Flaviano leva a reflexão feita por Luciana Sepúlveda (2005, p. 69) sobre "a dimensão simbólica dos objetos", segunda ela "Uma pessoa ao selecionar um objeto como peça de uma série, investe-o de valor. Este objeto passa a fazer parte de um "todo" imaginário, onde ocupa um lugar particular segundo uma determinada lógica". Porém, Todos os objetos dessa e das demais coleções possuem em si um "poder" de ligação com o mundo a partir da ideia de uso de quem o criou e até se tornarem um objeto museal percorrem um longo caminho. Luciana Sepúlveda (2005, p. 68) nos traz uma reflexão de Pormian, segundo a qual salienta que

[...] a natureza comum a todos estes objetos, por ele definidos como partes de uma coleção: todos realizam a ponte entre mundos diferentes, entre espaços e temporalidades, entre o mundo aqui e alhures, entre um tempo presente e um tempo passado, entre o mundo dos vivos e o mundo dos mortos, ou ainda, entre o mundo dos vivos e o mundo dos deuses. São todos, diz, semióforos. Objetos portadores de sentido, reveladores de outros mundos, vias de acesso.

Segundo Sepúlveda (2005) este "[...] fio de orientação entre tempo e espaço tecidos por Pormian, sugere um caminho para se 
Trajes do clero: diálogos sobre patrimônio, poder e comunicação

compreender a natureza do sentido atribuído aos objetos como peças de coleção", (p. 68) esta relação proporcionada pelo objeto seja com o colecionador ou com seus admiradores é uma relação entre o visível e o invisível, podemos concluir também entre o real e o imaginário.

Por fim, vale lembrar que ambas as peças aqui analisadas (Imagens 1 e 2) possuem valores intrínsecos e valores atribuídos, que com a pesquisa se tornam mais conhecidos e podem assim ser explorados tanto nas exposições, quanto nas atividades de ações educativas desenvolvidas nos museus. As peças da coleção também foram preservadas e hoje estão expostas num museu por motivos semelhantes, por serem objetos de grande valor estético, ou seja, valores intrínsecos, vistos pelos materiais utilizados em suas confecções o que diretamente está ligado às pessoas as quais pertenceram, na sua maioria bispos e cardeais pois, apesar de em sua maioria serem peças que podem ser usadas por simples sacerdotes, como por exemplo a casula, isso raramente acontece.

Mesmo com toda tecnologia e a forma com que peças desses tipos são confeccionadas nos dias de hoje (no lugar de pedras preciosas, pedras comuns, no lugar de ricos bordados à mão, bordados feitos por máquinas industriais) deixando muito mais acessíveis a todos os públicos de religiosos. Elas ainda continuam sendo consideradas caras para algumas paróquias, principalmente de bairros periféricos, subúrbios e pequenas cidades de interior que não possuem poderes aquisitivos para possuí-las em suas paróquias e dioceses e muitas vezes por falta de conhecimento dos valores simbólicos, acham desnecessários o uso de alguns paramentos, (como por exemplo, a casula de uso exclusivo dos sacerdotes e a dalmática de uso exclusivo dos diáconos) durante as celebrações litúrgicas.

\section{A hierarquia eclesiástica nos paramentos litúrgicos}


A Igreja católica através do sacramento da ordem ${ }^{9}$ institui três graus hierárquicos, são eles: o diaconato, o presbiterado e o episcopado, sendo que somente os dois últimos são instituídos sacerdotes. O diácono, por sua vez tem por missão auxiliar e servir os sacerdotes. "Os presbíteros (padres) e bispos (epíscopos), podem ainda participar de diversas funções e, além disso, ocupar cargos, aos quais são conferidos títulos, como por exemplo, as funções de arcebispo, Papa e a de cardeal, que são títulos atribuídos aos bispos" (Vale, 2016, p. 111). Estes podem ser distinguidos pelos trajes, insígnias e cores.

Aqui será apresentado de forma sintetizada as principais vestes dos ministros ordenados nos três graus hierárquicos e também aqueles que exercem outras funções, recebendo da Igreja títulos.

O menor grau na escala hierárquica é de diácono, esse pode ser facilmente reconhecido por simplesmente usar a estola "transversalmente por cima do ombro e a cruzar sob o braço direito, unindo por duas fitas ou cordões, colocados a cerca de 50 cm das extremidades, para manter nessa posição". (Rocca \& Guedes, 2004, p. 157). Estes, além da alva, ${ }^{10}$ paramento comum a todos os ministros usam também a dalmática (Imagem 3). Segundo as Instruções Gerais do Missal Romano (IGMR) "A veste própria do diácono é a dalmática que se veste sobre a alva e a estola; contudo por necessidade ou por menor grau de solenidade, a dalmática pode omitir-se". (Como citado por Vale, 2016, p. 116).

9 “Ordem é o sacramento graças ao qual a missão confiada por Cristo a seus Apóstolos continua sendo exercida na Igreja até o fim dos tempos; é, portanto, o sacramento do ministério apostólico. Comporta três graus: o episcopado, o presbiterado e o diaconado".(CIC , 1536).

10 ALVA: "Túnica com mangas comprida, normalmente de linho branco. Pode ser ornamentada com renda ou bordado na parte inferior e na extremidade das mangas. Usada sob a casula, dalmática e pluvial ou apenas com estola". (Alarcão \& Pereira, 2000, p. 53). 
Trajes do clero: diálogos sobre patrimônio, poder e comunicação

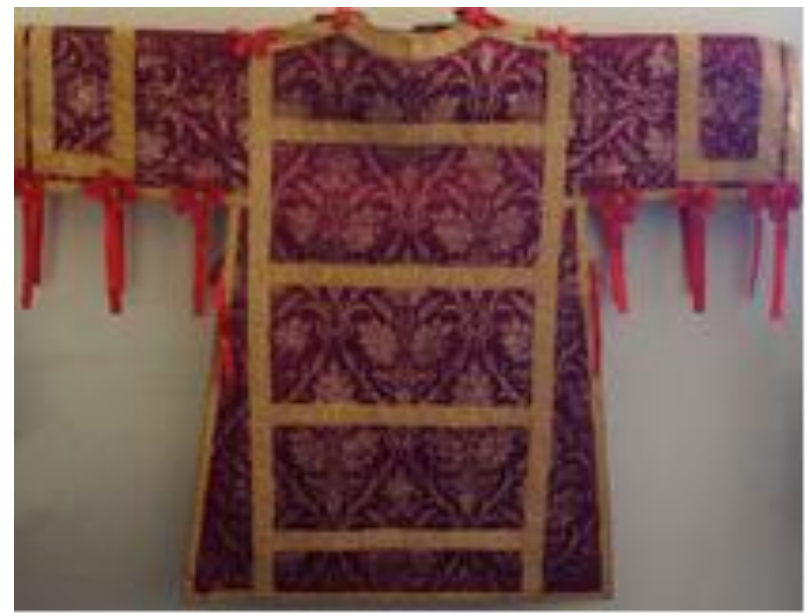

Imagem 3. Dalmáticas - acervo FIFB

Fotografia: Renilda S. do Vale.

Os presbíteros ou padres como são mais conhecidos, como veste eclesiástica usam a batina preta ou a camisa com colarinho. Na liturgia usam a alva, a estola caída sobre os ombros e a casula (Imagens 1 e 2). A casula é a veste própria dos presbíteros. Da mesma forma os bispos como veste eclesial usam a batina na tonalidade violáceo ou preta com detalhes violáceos, na liturgia geralmente são vistos trazendo sobre a cabeça o solidéu na cor violácea. Distinguem-se dos presbíteros por esses detalhes na cor e por levarem na altura do peito a cruz peitoral. ${ }^{11}$ "Os presbíteros (padres) e bispos (epíscopos) podem ainda participar de diversas funções e, além disso, ocupar cargos, aos quais são conferidos

${ }^{11}$ Cruz peitoral: é insígnia do bispo, distinguindo-se a do arcebispo por ter dois braços. (Falcão, D. Manuel Franco. Enciclopédia Católica Popular - Disponível em: http://sites.ecclesia.pt/catolicopedia/artigo.php?id entrada=86 
títulos, como por exemplo, as funções de arcebispo, Papa e a de cardeal, que são títulos atribuídos aos bispos" (Vale, 2016, p. 111). A veste eclesial do cardeal é a batina preta com detalhes e faixa na tonalidade vermelha.

$\mathrm{Na}$ hierarquia eclesial, o Papa é a maior autoridade, considerado o sucessor de São Pedro. O sumo pontífice tem como veste eclesiástica a batina e o solidéu na cor branca. Os paramentos litúrgicos usados por ele são semelhantes aos do bispo. Além deles o sumo pontífice é o único a usar fanone, ${ }^{12}$ e as insígnias: anel de pescador $^{13}$ e férula. ${ }^{14}$

Cada veste litúrgica tem seu valor simbólico, por elas os ministros da ordem são reconhecidos nos seus três graus, por elas também se reconhecem os títulos que são confiados a alguns desses ministros. Sendo assim reconhecidos pelos trajes o poder que lhe é pertinente. Ao Papa, sucessor de Pedro, na escala hierárquica é o mais importante representante da Igreja, visto como a própria denominação do nome diz, o pai e também o pastor de toda a Igreja. Aos Bispos cabem a "obrigação fazer visita ad limina apostolorum, uma visita aos túmulos dos apóstolos na Diocese de Roma, na qual apresentam ao Papa um relatório de sua diocese". Os bispos são considerados os sucessores dos apóstolos. Os presbíteros são subordinados aos Bispos. Segundo o Catecismo da Igreja Católica, os presbíteros "só podem exercer seu ministério na dependência do Bispo e em comunhão com ele" (CIC, 1567).

12 Fanone: veste exclusiva do Papa. De seda com riscas brancas e douradas, é constituída por duas romeiras sobrepostas, unidas no decote, ambas de corte circular, mas sendo a de cima mais curta e com chanfradura nas costas, orlada com galão de ouro e debruadas a arminho, à frente, apresenta uma cruz bordada a ouro. É vestida entre a alva e o roquete ou a casula, mas deixando passar a romeira de cima e cair sobre estes. (Rocca \& guedes, p. 173).

${ }^{13} \mathrm{O}$ anel usado pelo papa é denominado anel do pescador, traz a imagem de São Pedro gravada na frente.

14 Diferentemente dos bispos, o Sumo Pontífice não faz uso do báculo, mas da férula, uma haste munida de uma cruz na extremidade; 
Trajes do clero: diálogos sobre patrimônio, poder e comunicação

Dessa forma, a Igreja também comunica seja através dos trajes eclesiásticos ou através dos paramentos litúrgicos não só as mensagens bíblicas e teológicas de sua doutrina, mas também a força e o poder de cada ministro que o exerce, nos diferentes graus que podem ser confiados. As cores: branco para o Papa, vermelho para os cardeais, violáceo para os bispos e preto para os presbíteros, como foi visto, também contribuem para a distinção de cada ministro. Porém, todos eles durante a liturgia se submetem as cores do calendário litúrgico, ${ }^{15}$ utilizadas nos paramentos, a saber: a estola, a casula, a dalmática. Segundo Roque (2011):

As cores mantêm a expressão simbólica que confirma o sentido global das várias épocas litúrgicas, de acordo com a interpretação proposta pelo Papa Inocêncio III: o Branco além de ser a cor da alegria, simboliza, na Páscoa e na Ascensão, as vestes dos anjos e, nas festas das virgens e confessores, a pureza e a inocência; o vermelho, nas festas dos apóstolos e mártires, recorda o sangue do seu sacrifício e, no Pentecostes, evoca a caridade e o ardor do Espírito Santo. O verde, como cor intermédia entre o branco e o vermelho, corresponde ao tempo comum. (p. 196-197).

Apesar de todos os ministros utilizarem na liturgia a cor correspondente ao tempo litúrgico, eles podem ser distinguidos pelas insígnias que trazem. Tanto no plano do rito da liturgia, quanto no plano da hierarquia, os trajes eclesiásticos e litúrgicos

${ }^{15}$ Ano Litúrgico: o conceito foi cunhado no século XVI pelo pároco evangélico Johanes Pomarius e se distingue do ano civil pelas festas eclesiásticas e pela data

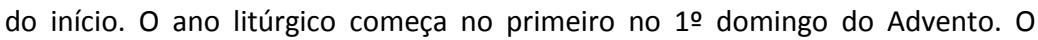
último domingo do ano litúrgico é a solenidade de Cristo Rei, que faz dirigir o olhar para a volta do Senhor. O ano litúrgico se compõe dos "Tempos próprios" do Natal e Páscoa, como também do assim chamado Tempo comum (com 33/34 domingos). O centro do ano litúrgico é a Páscoa, por ser a celebração da morte e ressurreição de Jesus Cristo, como centro da fé cristã. Seguindo a Parasceve judaica, é celebrada assim desde o século I. (Urban \& Bexten, 2013, p. 16). 
comunicam suas mensagens àqueles que participam da celebração. O que celebram? e quem celebra? São dois questionamentos que podem ser respondido apenas observando os paramentos dos sacerdotes que realizam a celebração.

\section{Conclusão}

São muitos os vieses de pesquisas e estudos que se pode traçar quando o assunto é vestuário, e parecem ainda incontáveis as discussões que são capazes de gerar, principalmente quando adentramos no viés psicológico e nas relações de poder que o vestuário proporciona. Certamente porque grande é o alcance simbólico e comunicacional deste objeto.

Em se tratando de trajes que pertencem a coleções de museus de tipologias religiosas, esse simbolismo talvez seja ainda mais forte. As peças são usadas para "falar", no caso da indumentária litúrgica católica, para falar no altar, durante o rito litúrgico. O formato das peças, as cores, as guarnições ${ }^{16}$ utilizadas e os símbolos cristãos impregnados nas vestes através dos bordados, pinturas e aplicações, juntos fazem com que essas peças colaborem

${ }^{16}$ Ou seja, adornos ou enfeites, no caso das indumentárias litúrgicas, geralmente feitos com galões, podendo ser: Galão bordado - executado sobre materiais de enchimento e destinado a rematar ou a decoração; Galão Franjado - Galão rematado por uma franja de diversas alturas; Galão tecido - Tipo de galão ou passamanaria executado em tear com fios de seda, linho ou algodão. 
Trajes do clero: diálogos sobre patrimônio, poder e comunicação

na ação litúrgica, seja durante as missas, ${ }^{17}$ seja durante a administração dos sacramentos. ${ }^{18}$

Com o passar do tempo essa linguagem nos paramentos foi se transformando. Das primeiras missas celebradas na Igreja primitiva aos dias de hoje, muita coisa mudou quando se trata dos paramentos e alfaias utilizadas no altar. Porém, valor inicial não muda, mas junta-se a estes novos valores atribuídos. Além disso, novos artefatos surgem e muitas vezes são acrescidos a eles novos significados. Por esses e tantos outros motivos a pesquisa parece nunca poder esgotar o assunto. Todavia, contribui significativamente para torna-lo pelo menos para os museus e instituições que possuem coleções dessa tipologia, muito mais atrativos aos olhos de quem aprecia.

\section{Referências}

Alarcão, T. \& Pereira, (2000). Normas de Inventário Texteis - Artes Plásticas e Artes Decorativas. (2 $\underline{a}$ ed.). Lisboa: Instituto Português de Museus.

17 Missa: O termo M., derivado do lat. "missio", com sentido de despedida e de envio, designa a *celebração do *sacramento da *Eucaristia (ou *mistério pascal) sobretudo na dimensão sacrificial. Inicialmente usaram-se outros termos, como "fracção do pão" (Act 2, 42; 20,7), "ceia do Senhor" (1Cor 11, 20), "acção", "oblação", "sacrifício" ou "sacrifício eucarístico". (Falcão, D. Manuel Franco. Enciclopédia Católica Popular - Disponível em: http://www.portal.ecclesia.pt/catolicopedia).

${ }^{18}$ Sacramento: São sinais da presença e atuação de Deus na Igreja e em cada um de nós. A Igreja conhece os sete sacramentos desde a idade Média: batismo, crisma, eucaristia, penitência, unção dos enfermos, ordem (para diaconato, presbiteriato, episcopado), matrimônio. [...]. (Urban \& Bexten. 2013, p. 236). 
Associação Cultural de Amigos do Museu Casa de Portinari (2010). Documentação e conservação de acervos museológicos: diretrizes. Brodowski: ACAM Portinari; São Paulo: Secretaria de Estado da Cultura de São Paulo.

Bexten, M. \& Urban, A. (2013). Pequeno dicionário de liturgia. Aparecida: Ed. Santuário.

Bhabha, H. (1998). O local da cultura. Belo Horizonte: Ed. UFMG.

Burke, P. (2005). O que é história cultural? Rio de Janeiro: Zahar Ed.. Campbell, J. (1990). O poder do mito. In B. S. Flowers (C. F. Moisés, Trad.). São Paulo: Palas Athena.

Carvajal, F. A. (Org.). (2000). La Restauración de textiles en Colombia. in Facultad de Restauración de Bienes Muebles. Bogotá: Universidad Externado de Colombia.

Carvajal, F. A. (Org.). (2000). Catecismo da Igreja Católica (CIC). São Paulo: Edições Loyola.

Coppola, S. (2006). Costurando a memória: o acervo têxtil do Museu Arquidiocesano de Arte Sacra de Mariana. Belo Horizonte: Escola de belas Artes/UFMG.

Crane, D (2006). A moda e seu papel social: classe, gênero e identidade das roupas. São Paulo: Senac São Paulo.

Hostalácio, D. (2015). A simbologia das Togas. Belo Horizonte: Secretaria do Tribunal de Justiça do Estado de Minas Gerais. Disponível em: http://www.tjmg.jus.br

Instrução Geral do Missal Romano (IGMR). (2002). Tradução portuguesa para o Brasil da separata da terceira edição típica sob os cuidados da Congregação para o Culto Divino e a Disciplina dos Sacramentos, Roma.

Oliveira, A. (2009). Museologia e Ciência da Informação: distinções e encontros entre áreas a partir da documentação de um conjunto de peças de 'roupas brancas'.

Pearce, S. (2005). Pensando sobre objetos. In M. Granato \& C. P. dos Santos. Museu: instituição de pesquisa. (Mast Colloquia, v. 
Trajes do clero: diálogos sobre patrimônio, poder e comunicação

7, pp. 13-19). Rio de Janeiro: Museu de Astronomia e Ciências Afins.

Rocca, S.; Guedes, N. (Ed. ) (2004). Thesaurus: Vocabulário de Objetos do Culto Católico. Lisboa: Universidade Católica Portuguesa; Fundação da Casa de Bragança.

Ramos, F. (2004). A danação do objeto: o museu no ensino da história. Argos - Ed. Universitária Unochapecó

Roque, M. I. (2011). O sagrado no museu. Lisboa: Ed. Universidade Católica.

Sepúlveda, L. (2005). Coleções que foram museus, museus sem coleção, afinal que relações possíveis. In M. Granato \& C. P. dos Santos. Museu: instituição de pesquisa. (Mast Colloquia, v. 7, pp. 68-69). Rio de Janeiro: Museu de Astronomia e Ciências Afins.

Sheiner, T. (2005). Museologia e pesquisa: perspectiva na atualidade. In M. Granato \& C. P. dos Santos. Museu: instituição de pesquisa. (Mast Colloquia, v. 7). Rio de Janeiro: Museu de Astronomia e Ciências Afins.

Vale, R. (2016). Memória da fé: a coleção de paramentos litúrgicos do museu do traje e do têxtil da Fundação Instituto Feminino da Bahia. Salvador: FFCH /UFB. 